\title{
Thrombospondin 1 in hypoxia-conditioned media blocks the growth of human microvascular endothelial cells and is increased in systemic sclerosis tissues
}

Luke Morgan-Rowe, Joanna Nikitorowicz, Xu Shiwen, Andrew Leask, Janice Tsui, David Abraham and Richard Stratton ${ }^{*}$

\begin{abstract}
Background: Systemic sclerosis (SSC) is a chronic inflammatory autoimmune disease characterised by vascular dysfunction and damage, excess collagen deposition and subsequent organ manifestations. Vasculopathy is an early feature of the disease which leads to a chronic hypoxic environment in the tissues. Paradoxically, there is a lack of angiogenesis. We hypothesised that this may in part be due to a nonphysiological, overriding upregulation in antiangiogenic factors produced by the hypoxic tissues. We considered thrombospondin 1 (TSP-1) as a candidate antiangiogenic factor.

Results: Conditioned media from human microvascular endothelial cells cultured in both normoxic and hypoxic environments were able to block endothelial cell proliferation, with the latter environment having a more profound effect. Filtration to remove $>100-k D a$ proteins or heparin-binding proteins from the conditioned media eliminated their antiproliferative effect. TSP-1 was expressed in high concentrations in the hypoxic media, as was vascular endothelial growth factor (VEGF). Depletion of TSP-1 from the media by immunoprecipitation reduced the antiproliferative effect. We then show that, in a dose-dependent fashion, recombinant TSP-1 blocks the proliferation of endothelial cells. Immunohistochemistry of skin biopsy material revealed that TSP-1 expression was significantly higher throughout the skin of patients with SSc compared with healthy controls.
\end{abstract}

Conclusions: Despite the environment of chronic tissue hypoxia in SSc, there is a paradoxical absence of angiogenesis. This is thought to be due in part to aberrant expression of antiangiogenic factors, including TSP-1. We have demonstrated that TSP-1 is released in high concentrations by hypoxic endothelial cells. The conditioned media from these cells is able to block proliferation and induce apoptosis in microvascular endothelial cells, an effect that is reduced when TSP-1 is immunoprecipitated out. Further, we have shown that recombinant TSP-1 is able to block proliferation and induce apoptosis at concentrations consistent with those found in the plasma of patients with SSC and that its effect occurs in the presence of elevated VEGF levels. Taken together, these data are consistent with a model wherein injured microvascular cells in SSC fail to repair because of dysregulated induction of TSP-1 in the hypoxic tissues.

\section{Background}

Systemic sclerosis (SSc) is a chronic inflammatory autoimmune disease characterised by vascular dysfunction and damage, excess collagen deposition and subsequent organ manifestations [1]. The pathogenesis of SSc has

\footnotetext{
* Correspondence: r.stratton@medsch.ucl.ac.uk
Centre for Rheumatology Research and Connective Tissue Diseases, The

* Correspondence: r.stratton@medsch.ucl.ac.uk
Centre for Rheumatology Research and Connective Tissue Diseases, The Royal Free Hospital Campus, University College London, Pond Street, London NW3 2QG, UK
}

(c) 2011 Morgan-Rowe et al; licensee BioMed Central Ltd. This is an Open Access article distributed under the terms of the Creative Commons Attribution License (http://creativecommons.org/licenses/by/2.0), which permits unrestricted use, distribution, and reproduction in any medium, provided the original work is properly cited. the disease and precedes fibrosi terised by both abnormal vascular tone and endothelial cell damage [3]. Endothelial apoptosis is seen in recentonset SSc patients' dermal biopsies [4]. Anti-endothelial cell antibodies have been detected in some but not all patients with SSc [5]. These antibodies are capable of upregulating the expression of endothelial cell adhesion molecules and inducing apoptosis [6]. 
Other sources of early endothelial cell damage include reactive oxygen species, markers of which are found in the serum and urine of patients with SSc at higher levels than in controls $[7,8]$. In addition, nitric oxide synthesis by endothelial cells is dysregulated in SSc because of suppression of the endogenous nitric oxide synthetase and upregulation of the inducible isoform. Because of this, proteins and lipids can become damaged in SSc by oxidation or nitrosylation [9].

Vascular damage clinically manifests in early SSc as Raynaud's phenomenon, sometimes seen many years before the other features develop [10]. In addition, nailfold capillaroscopy is abnormal in early SSc, reflecting the endothelial vascular damage. The characteristic features of nailfold capillaroscopy in SSc include the presence of abnormal tortuous microvascular loops, the progressive loss of capillary density and areas of microvascular loss. Despite the chronic hypoxic environment and increased levels of proangiogenic vascular endothelial growth factor (VEGF) and its receptors, there is a failure of endothelial repair and an absence of angiogenesis in SSc $[11,12]$.

It has been postulated that the failure of angiogenesis in SSc may be due to a nonphysiological, overriding influence of antiangiogenic factors, which are present in high concentrations in the sera of patients with SSc [13-15]. Furthermore, plasma from patients with SSc has been shown to inhibit the migration and proliferation of microvascular endothelial cells [16].

Because of this, we became interested in the idea that hypoxic tissues are capable of releasing factors which interfere with reparative angiogenesis. We have gone on to test whether media from human cells cultured under hypoxic conditions can interfere with the growth of endothelial cells and whether the candidate antiangiogenic factor thrombospondin 1 (TSP-1) is induced in hypoxic cells or in the involved tissues of SSc patients.

\section{Methods}

\section{Cell culture}

The extended lifespan simian virus 40 transfected dermal human microvascular endothelial cell 1 (HMEC-1) cell line was employed. This line was generated by Ades et al. [17] and has been shown to maintain the phenotypic characteristics of small-vessel endothelial cells. For experiments, HMEC-1 cells were cultured in DMEM (Autogen Bioclear UK Ltd, Caine, Wiltshire, UK) with 10\% FCS, 2 mM L-glutamine, $1 \mathrm{mM}$ sodium pyruvate, $100 \mathrm{U} / \mathrm{mL}$ penicillin and $100 \mu \mathrm{g} / \mathrm{mL}$ streptomycin.

Cells were examined regularly by using phase contrast microscopy. Preparations which had reached confluence were trypsinised for secondary culture. Preparations which appeared to be infected by bacteria or failed to reach confluence after five days were discarded. Cells were passaged at confluence using $10 \%$ trypsin and split into equal thirds. The $\mathrm{C}_{2} \mathrm{C}_{12}$ mouse myoblast line 19 was also used. $\mathrm{C}_{2} \mathrm{C}_{12}$ cells were cultured on $0.01 \%$ gelatine plates in DMEM supplemented with $10 \%$ FCS, 2 $\mathrm{mM}$ L-glutamine, $1 \mathrm{mM}$ sodium pyruvate, $100 \mathrm{U} / \mathrm{mL}$ penicillin and $100 \mu \mathrm{g} / \mathrm{mL}$ streptomycin.

\section{Hypoxic culture}

Cells were cultured in a custom-made hypoxic chamber placed within a tissue culture incubator and maintained at $37^{\circ} \mathrm{C}$. The cells were plated onto $100-\mathrm{mm}$ tissue culture plates and placed within the chamber, which had been primed for one hour by flushing with $4 \% \mathrm{CO}_{2}, 1 \% \mathrm{O}_{2}$ and $95 \% \mathrm{~N}_{2}$. The chamber was then sealed, and hypoxic conditions were maintained for a further 24 hours prior to removal of the media for assay. Media were removed at the end of 24 hours of hypoxic culture for gas analysis and were found to have the following values (means \pm SEM): $\mathrm{pH} 7.41 \pm$ $0.04, \mathrm{pO}_{2} 6.4 \pm 0.8 \mathrm{kPa}$ and $\mathrm{pCO}_{2} 5.2 \pm 1.2 \mathrm{kPa}$. By comparison, media following culture under standard normoxic conditions for 24 hours had the following values (means $\pm \mathrm{SEM}$ ): $\mathrm{pH} 7.42 \pm 0.04, \mathrm{pO}_{2} 16.2 \pm 1.1$ $\mathrm{kPa}$ and $\mathrm{pCO}_{2} 4.8 \pm 1.6 \mathrm{kPa}$.

\section{Endothelial cell proliferation}

HMEC-1 cells were harvested at $80 \%$ confluence and plated at $5 \times 10^{4}$ cells/well in 12 -well plates, cultured for 24 hours and then cultured further in the presence or absence of $10 \%$ FCS with or without conditioned media from endothelial cells or skeletal muscle cells to test for antiproliferative effects of the conditioned media. After 24 hours of incubation, the cells were harvested by trypsinisation and counted in a haemocytometer. Each experiment was performed in triplicate.

In further experiments, HMEC-1 cells were cultured on 96-well plates with or without conditioned media from endothelial cells or with various concentrations of recombinant TSP-1 (R\&D Systems Minneapolis, MN, USA). The number of viable cells was measured by WST-1 assay. In this assay, a tetrazolium dye undergoes a colour change depending on the presence of viable mitochondria. Ten microlitres of WST-1 were added to each well, and the cells were incubated for a further two hours. The colour intensity was read at $450 \mathrm{~nm}$ (reference wavelength $655 \mathrm{~nm}$ ) in an ELISA plate reader.

\section{Assay for TSP-1 and VEGF}

Media were removed and assayed for TSP-1 and VEGF by ELISA (R\&D Systems Pharmacia Biotech, Little Chalfont, UK). Experiments were performed in triplicate, and samples were assayed in duplicate according to the manufacturer's instructions. Standard curves were included in each assay plate. 


\section{Western blot analysis}

Western lysate samples of $20 \mu \mathrm{L}$ containing $10 \mu \mathrm{g}$ of protein were run upon a ready-cast $4 \%$ to $12 \%$ Tris-Glycine gel (Novex. Ontario, Canada) alongside a broadrange protein marker (New England Biotech, Wakefield, MA, USA) at $125 \mathrm{~V}$ until the dye front had reached the bottom of the gel (approximately 1.5 hours) in Tris-Glycine Running Buffer (Invitrogen, Carlsbad, CA, USA). Proteins were electrophoretically transferred to nitrocellulose Hybond-C (Amersham Pharmacia, Little ChalfontBuckinghamshire, UK). Each membrane was briefly washed, and then nonspecific protein binding was blocked by one-hour incubation with $10 \%$ milk protein in PBS. Membranes were probed with antibodies against caspase 3 and cleaved caspase 3 (\#9662 and \#9661S; New England Biolabs, Wakefield, MA, USA), and binding was detected using labelled species-specific secondary antibody followed by avidin-biotin complex detection assay (Amersham Pharmacia).

\section{Quantitative RT-PCR analysis}

HMEC-1 were cultured to $90 \%$ confluence and incubated overnight in hypoxic $\left(1 \% \mathrm{O}_{2}\right.$ and $\left.5 \% \mathrm{CO}_{2}\right)$ or normal conditions at $37^{\circ} \mathrm{C}$. RNA was extracted from cells using the RNeasy Kit (Qiagen, Crawley West Sussex, UK), and the quality was evaluated on the Agilent 2100 Bioanalyzer (Agilent Technologies Edinburgh, UK). One microgram of RNA extracted from each well was reverse-transcribed using the QuantiTect Reverse Transcription Kit (Qiagen). qPCR was performed in triplicate using the SensiMix SYBR kit (Bioline, London, UK) on the Rotor-Gene 6000 (Qiagen, Crawley West Sussex, $\mathrm{UK})$, and data were normalised against expression of $T U B B$ and SDHA. The reference genes were chosen using genorm ${ }^{\text {PLUS }}$ software (Biogazelle, Ghent, Netherlands). The qRT-PCR conditions were 40 cycles at $95^{\circ} \mathrm{C}$ for 10 minutes, $95^{\circ} \mathrm{C}$ for 10 seconds, $60^{\circ} \mathrm{C}$ for $15 \mathrm{sec}$ onds and $72^{\circ} \mathrm{C}$ for 20 seconds. The primers used are shown in Table 1.

\section{Immunohistochemistry}

For immunofluorescence, sections were permeabilised by washing three times in cold PBS containing $0.3 \%$ Triton $\mathrm{X}-100$ at room temperature for 5 minutes, then washing them further in PBS containing 0.1\% Tween.

Table 1 Primers used for qRT-PCR

\begin{tabular}{lll}
\hline Gene & Primer & Sequence \\
\hline THBS1 & Forward & CTGACCTGAATACGAATGTAGAGA \\
& Reverse & TITCTCAAGCCCATAGTTCCAGAAG \\
TUBB & Forward & ACATACCTGAGGCGAGCAA \\
& Reverse & TCACTGATCACCTCCCAGAA \\
SDHA & Forward & AGAAGCCCTITAGGAGCA \\
& Reverse & CGATCACGGGTCTATATTCCAGA \\
\hline
\end{tabular}

Nonspecific binding sides were blocked with 3\% BSA and $10 \%$ serum in PBS with Tween for 30 minutes. Sections were immunostained with rabbit polyclonal antiTSP-1 antibody (\#sc-14013; Santa Cruz Biotechnology, Santa Cruz, CA, USA) overnight at $4^{\circ} \mathrm{C}$. As a negative control, samples were incubated with polyclonal rabbit immunoglobulin G (Vector Laboratories, Burlingame, CA, USA). Sections were incubated with Alexa Fluor 568- or Alexa Fluor 594-labelled anti-rabbit antibody (Molecular Probes/Invitrogen, Eugene, OR, USA) (1:1000) for one hour. Nuclei were stained for 4,6-diamidino-2-phenylindole (Sigma-Aldrich, St Louis, MO, USA) for 10 minutes. Glass coverslips were mounted onto slides with Vector aqueous anti-fade VECTASHIELD fluorescence mounting medium (Vector Laboratories) and sealed with nail polish. Sections were imaged with an Zeiss Axioplan microscope (Carl Zeiss, Heidenheim, Germany) at $\times 40$ original magnification.

\section{Results}

Conditioned media from hypoxic endothelial cells block proliferation

We began by testing whether media from hypoxic cells could block cellular proliferation. HMEC-1 endothelial cells and $\mathrm{C}_{2} \mathrm{C}_{12}$ muscle cells were cultured to confluence in $75-\mathrm{cm}^{2}$ flasks under normoxic or hypoxic conditions. After 24 hours, media were removed and transferred to proliferating HMEC-1 cells grown on six-well plates in $10 \%$ FCS. Culture under serum-free conditions was used as a negative control, and medium plus $10 \%$ FCS was used as a positive control. Conditioned media from HMEC-1 but not from $\mathrm{C}_{2} \mathrm{C}_{12}$ cells inhibited cellular proliferation. This effect was more marked when conditioned media from hypoxic HMEC-1 cells were used, and these were found to abolish proliferation (Figure 1). In addition, cells cultured in media transferred from hypoxic HMEC-1 cells took on an altered morphology with more rounding up of cells (Figure 1).

\section{Antiproliferative effect of hypoxia-conditioned media is due to a heparin-binding macromolecule}

Because of the above-described findings, we became interested in identifying which factor released by hypoxic HMEC-1 cells was responsible for the suppression of cell proliferation and for the change in cellular morphology. Further experiments were performed using filtration to remove protein factors $>10 \mathrm{kDa}$ and $>100$ $\mathrm{kDa}$ and using heparin Sepharose beads to precipitate and remove heparin-binding factors. Media were transferred to proliferating HMEC-1 cells grown on 96-well plates, and cell numbers were assayed after 24 hours by WST-1 assay and imaged using a Zeiss Axio Scope (Carl Zeiss). Filtration to remove $>10-k D a$ factors was found to eliminate the antiproliferative effect of 


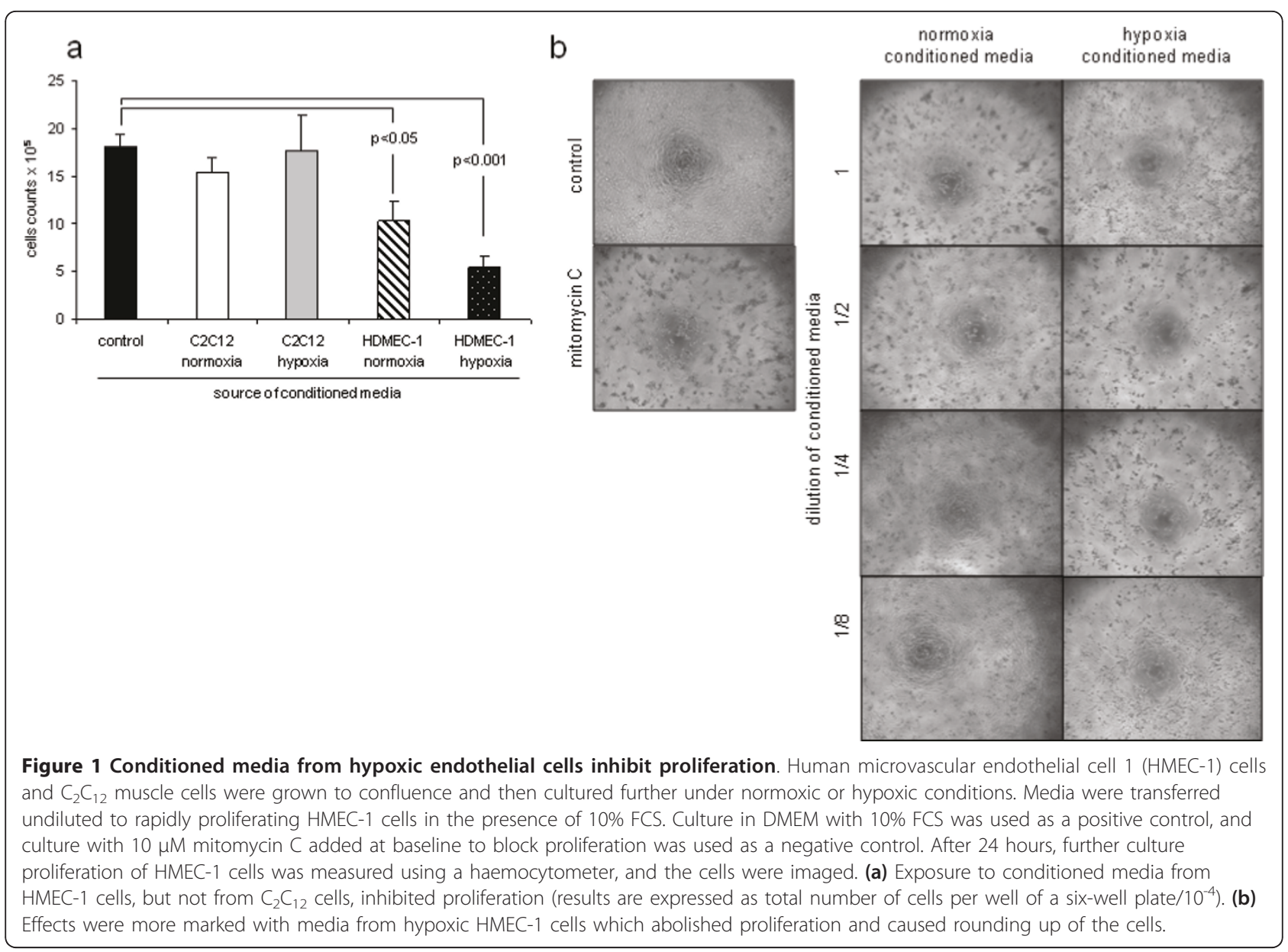

hypoxia-conditioned media and to block the morphological changes induced (Figure 2). Because of this, we concluded that the effects were not simply due to degradation of the hypoxia-conditioned media. Filtration of $>$ $100-\mathrm{kDa}$ factors was also found to abolish the antiproliferative effects of hypoxia-conditioned media (Figure 2). In addition, removal of heparin-binding proteins using heparin Sepharose beads led to loss of the antiproliferative effect of the media (Figure 2). We concluded that the antiproliferative effect of the hypoxia-conditioned media was due to the presence of heparin-binding macromolecules $>100 \mathrm{kDa}$.

\section{TSP-1 is induced in hypoxia-conditioned media and blocks proliferation of HMEC-1 cells}

Because we found that the antiproliferative effects were due to the presence of a large heparin-binding factor, and because TSP-1 is believed to promote endothelial cell apoptosis, we considered TSP-1 as a candidate factor responsible for the antiproliferative effect and change in cellular morphology induced by hypoxia-conditioned media. We assayed levels of TSP-1 in media from
HMEC-1 cells grown under normoxic and hypoxic conditions. TSP-1 was present in the media of normoxic HMEC-1 cells and was induced following 24 hours in hypoxic culture (mean \pm SEM TSP-1 in normoxic HMEC-1 media $569 \pm 37 \mathrm{ng} / \mathrm{mL}$, mean \pm SEM TSP-1 in hypoxic HMEC-1 media $775 \pm 25 \mathrm{ng} / \mathrm{mL} ; P<0.004$ ) (Figure 3). As expected, the hypoxic culture conditions led to an induction of VEGF, and levels of VEGF were increased in the hypoxic HMEC-1 media (mean \pm SEM VEGF in normoxic HMEC- 1 media $184 \pm 54 \mathrm{pg} / \mathrm{mL}$, mean \pm SEM VEGF in hypoxic HMEC-1 media $447 \pm$ $22 \mathrm{pg} / \mathrm{mL}$, SEM; $P<0.01$ ) (Figure 3 ).

In addition, TSP-1 mRNA levels in HMEC-1 cells cultured under normoxic and hypoxic conditions were assayed by qRT-PCR. Culture under hypoxic conditions for 24 hours led to the induction of TSP-1 expression (mean \pm SEM normoxic cell TSP-1 copy number $3.19 \pm$ 0.41 , mean \pm SEM hypoxic culture copy number $8.98 \pm$ 2.39; $P<0.0035$ ) (Figure 3).

Next we measured whether recombinant TSP-1 is able to block the proliferation of HMEC-1 cells. TSP-1 blocked, in a dose-dependent fashion, the proliferation 


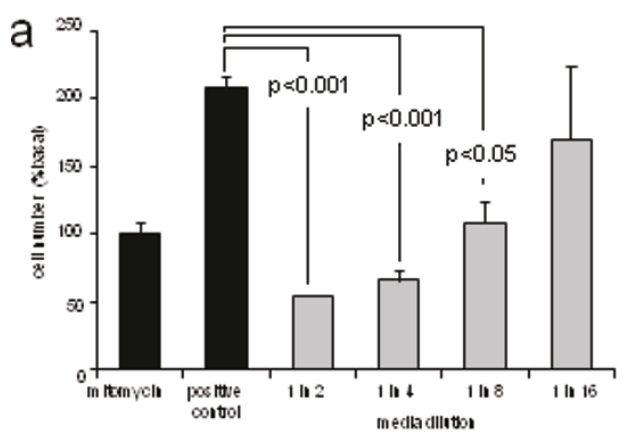

d
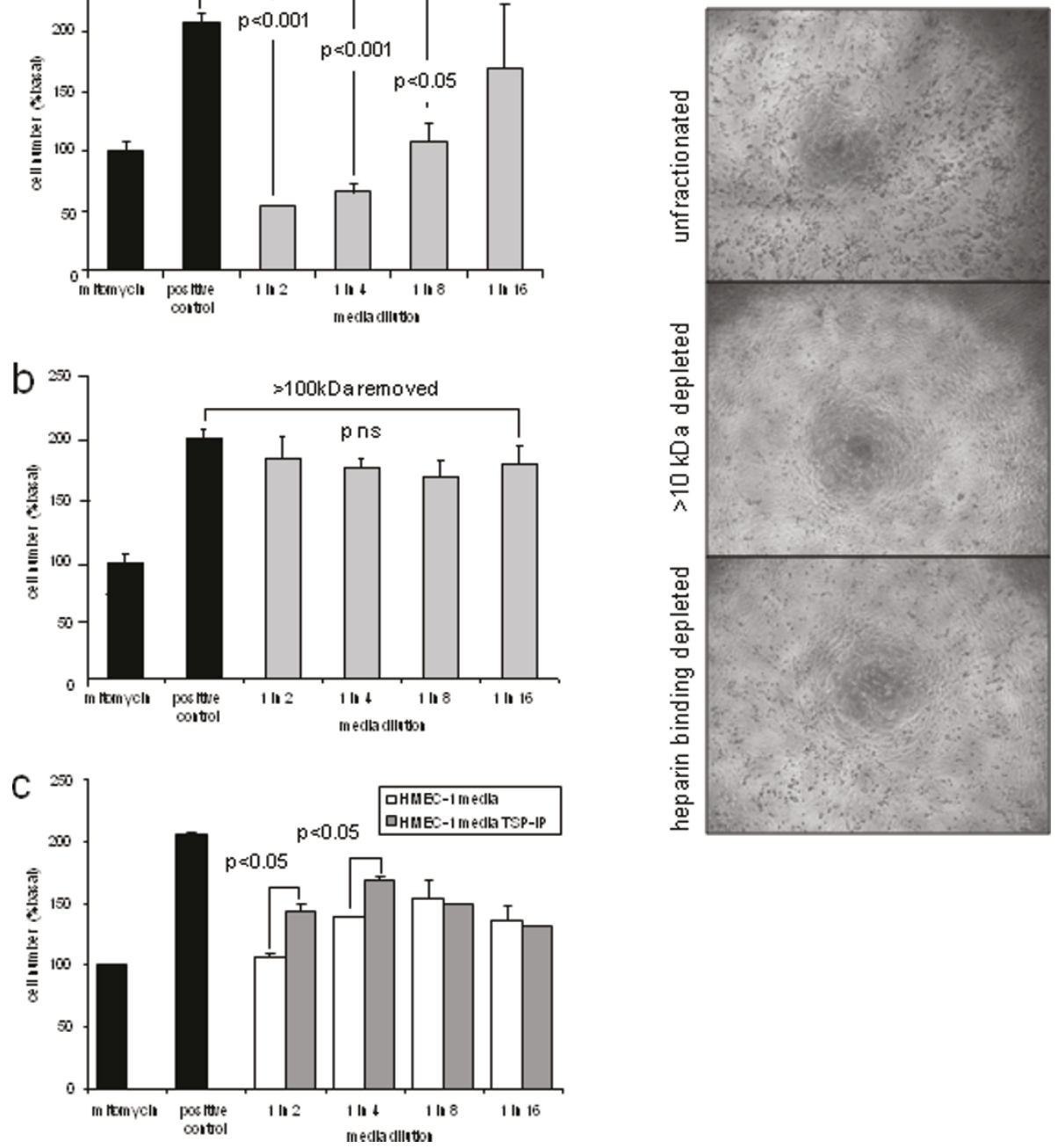

Figure 2 Suppression of proliferation by endothelial cell-conditioned media is due in part to presence of heparin-binding macromolecule. (a) In further experiments, HMEC-1 were cultured on 96-well plates in the presence of 10\% FCS to promote proliferation. Treatment with mitomycin $C$ at baseline was used as a negative control. Addition of conditioned media from hypoxic HMEC-1 blocked proliferation. (b) Filtration to remove molecules $>10 \mathrm{kDa}$, or heparin binding molecules blocked the effect of hypoxia conditioned media on morphology of treated cells. (c) In further experiments, filtration was used to remove molecules $>100 \mathrm{kDa}$ or (d) immunoprecipitation of TSP-1 antagonised the antiproliferative effects of the conditioned media.

of HMEC-1 cells grown on 96-well plates in the presence of $10 \%$ FCS (Figure 4). Full suppression of proliferation was seen with $100 \mathrm{ng} / \mathrm{mL}$ TSP- 1 and partial suppression was observed with $50 \mathrm{ng} / \mathrm{mL}$ TSP-1. In addition, immunoprecipitation of TSP-1 from conditioned media blocked some but not all of the antiproliferative effect (Figure 2). Because we suspected that TSP-1 and hypoxia-conditioned media were causing apoptosis, we measured the effect of TSP-1 and hypoxia-conditioned media on cleaved caspase 3 levels in HMEC-1 cells. Both TSP-1 and hypoxia-conditioned media led to increased levels of cleaved caspase 3 in HMEC-1 cells after 16 hours of culture (Figure 4). We concluded that TSP-1 is induced following culture of HMEC-1 cells in hypoxia and that TSP-1 blocks the proliferation of HMEC-1 cells and causes apoptosis, despite the elevation of VEGF.

TSP-1 is expressed by endothelial cells in normal skin and is induced in SSc-involved tissues

Because of the above-described findings, we became interested in the idea that similar effects might be occurring in SSc patients and that TSP-1 might be induced in the ischaemia-involved SSc tissues. We next performed immunohistochemistry to stain healthy control skin biopsy material and SSc-involved forearm 

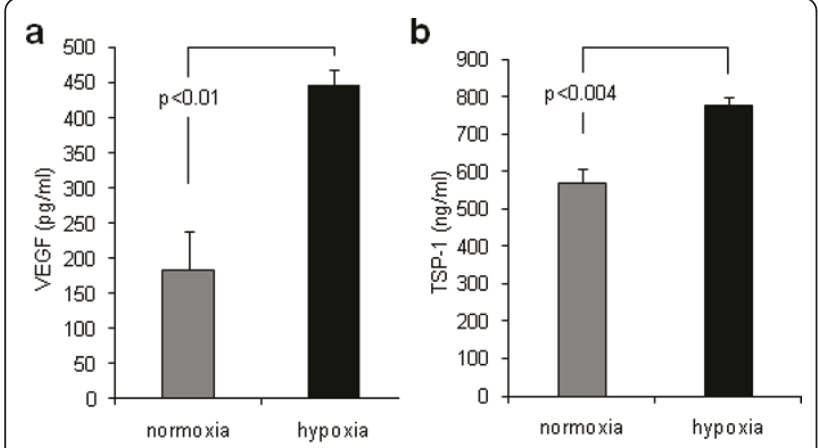

C

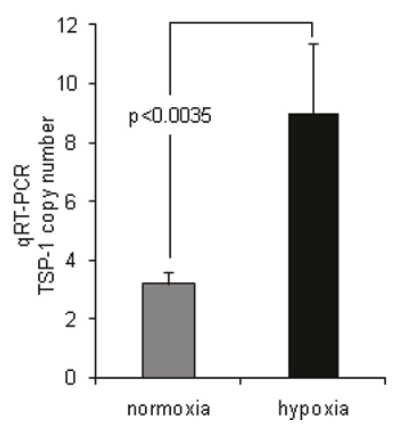

Figure 3 Induction of VEGF and TSP-1 in the media of HMEC-1 cells cultured under hypoxic conditions. Conditioned media from confluent HMEC-1 grown under normoxic or hypoxic culture conditions were assayed by ELISA for VEGF and TSP-1. Hypoxic culture (24 hours) was associated with increased levels of both (a) VEGF (mean \pm SEM VEGF in normoxic conditions $184 \pm 54 \mathrm{pg} / \mathrm{mL}$, mean \pm SEM VEGF in hypoxic conditions $447 \pm 22 \mathrm{pg} / \mathrm{mL} ; P<0.05$ ) and (b) TSP-1 (mean \pm SEM TSP-1 in normoxic conditions $569 \pm 37$ $\mathrm{pg} / \mathrm{mL}$, mean \pm SEM TSP-1 in hypoxic conditions $775 \pm 24.5 \mathrm{pg} / \mathrm{mL}$; $P<0.003$ ). (c) In addition, TSP-1 mRNA levels were assayed by performing qRT-PCR. Hypoxic culture led to increased TSP-1 mRNA levels (mean \pm SEM TSP-1 copy number in normoxia $3.19 \pm 0.41$, mean \pm SEM TSP-1 copy number in hypoxia $8.98 \pm 2.39 ; P<0.004)$. skin for the presence of TSP-1 using a monoclonal anti-TSP-1 antibody. In healthy control skin, positive staining for TSP-1 was seen in the dermal microvasculature but was otherwise absent. By contrast, in SScinvolved skin, TSP-1-positive staining was observed in endothelial cells, epidermal keratinocytes and dermal connective tissue cells (Figure 5). We concluded that TSP-1 was being induced in the SSc dermis and epidermis.

Also, we wanted to test whether free TSP-1 was present in the dermal interstitial fluid sampled from SSc and healthy control skin. In fact, in dermal interstitial fluids, TSP-1 was present only at very low levels and appeared absent from SSc dermal fluid (data not shown). We concluded that while TSP-1 was abundant within the dermis and epidermis in SSc, it was present only at low levels as a free, non-matrix-associated factor in the extracellular fluid.

\section{Discussion}

Hallmarks of SSc are tissue ischaemia due to vascular injury, remodelling and stenosis; increased vascular tone; and microvascular damage. Despite the endothelial cell damage and activation and the ensuing chronic hypoxic environment, there is a failure of angiogenesis in SSc. It has been hypothesised that this might be due in part to an aberrant expression of antiangiogenic factors, and we have sought to investigate further the antiangiogenic effects of TSP-1 in the disease.

TSP-1 is derived from a large trimeric glycoprotein and functions as an adhesive matricellular factor modifying the binding of a variety of cells to extracellular matrix proteins $[18,19]$. TSP-1 has multiple binding sites, including an amino terminal heparin-binding domain, a procollagen domain, epidermal growth factor-like repeats and

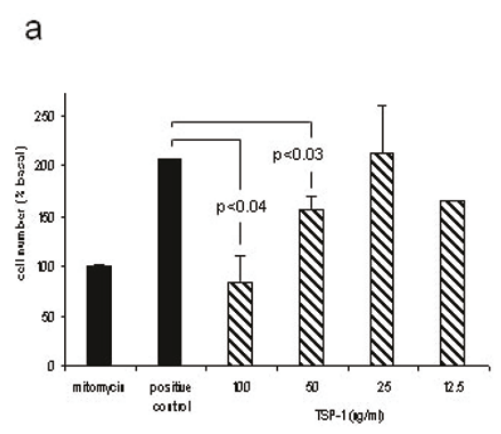

b

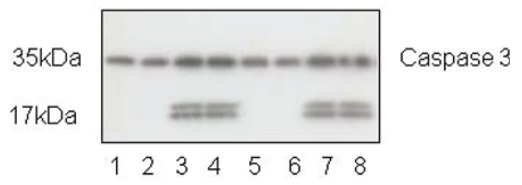

$\begin{array}{ll}1,2 & \text { Control } \\ 3,4 & \text { Hypoxia media } \\ 5,6 & \text { Normoxia media } \\ \text { 7,8 } & \text { TSP-1 } 100 \mathrm{ng} / \mathrm{ml}\end{array}$

Figure 4 Addition of recombinant TSP-1 to proliferating endothelial cells blocks proliferation and induces apoptosis. (a) Recombinant human TSP-1 was added to rapidly proliferating HMEC-1 cells grown on 96-well plates in the presence of 10\% FCS, and cell numbers were assessed by performing a WST-1 assay after 24 hours of further culture. The addition of TSP-1 suppressed proliferation in a dose-dependent manner. (b) In other experiments, proliferating HMEC-1 cells were treated with TSP-1 or conditioned media from cultured HMEC-1 cells and then lysed after 16 hours for Western blot analysis for cleaved caspase 3. Exposure to both TSP-1 and hypoxia-conditioned media led to elevation of cleaved caspase 3 in the cells, consistent with the induction of apoptosis. ${ }^{*} P<0.04$. ${ }^{* *} P<0.03$. 

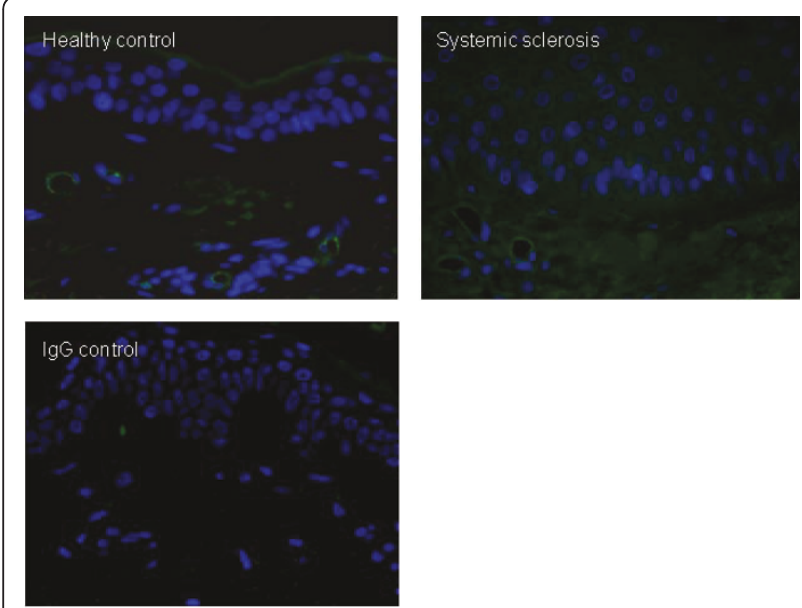

green thrombospondin-1

blue DAPI

Figure 5 TSP-1 is increased in the involved forearm skin of SSC patients. Skin biopsies from SSc patients and healthy controls ( $n=$ 5 for each group) were stained by immunohistochemistry using a primary antibody against TSP-1. In healthy controls, positive staining was seen around endothelial cells in the dermis. In SSc sections, TSP-1 was increased and expressed in endothelial cells, epidermal keratinocytes and cells of the dermis. Isotype-matched antirabbit IgG polyclonal antibody was included as a control.

an RGD (arginine-glycine-aspartic acid) integrin-binding region [20]. The binding of TSP-1 to fibronectin, fibrinogen, laminin and collagen 5 has been described [21,22]. TSP-1 is released from granules of platelets, from endothelial cells and from other cells, including keratinocytes and fibroblasts $[23,24]$. Diverse functions of TSP-1 have been defined, including the adhesion of platelets to thrombin-containing clots, targeting of cells for apoptosis and clearance of apoptotic cells by macrophages [25]. Studies of TSP-1-knockout mice have demonstrated that wounds heal more slowly and irregularly because of prolonged inflammation, delayed closure, scab loss and reepithelialisation. In hindlimb ischaemia in the TSP-1knockout mice, enhanced angiogenesis and improved blood flow were shown [26,27].

We were interested to find that when media from microvascular human endothelial cells cultured in hypoxia were added to proliferating endothelial cells, proliferation was blocked and apoptosis was induced. These effects were not observed when media from hypoxic muscle cells were used. This suggests the presence of a factor released by the hypoxic endothelial cells which was blocking proliferation. This effect was reduced by diluting the conditioning media, removing proteins that bind heparin and filtering large molecular weight proteins. This led us to consider whether TSP1 , a large glycoprotein with a heparin-binding domain, was a component of the culture media contributing to its antiproliferative and apoptotic effect. In keeping with this idea, we found that the concentration of TSP-1 was increased in media from hypoxic endothelial cells compared with normoxic endothelial cells and that TSP-1 mRNA levels were induced by hypoxic culture. Also, depletion of TSP-1 by immunoprecipitation partially blocked the inhibition of proliferation. These data are consistent with those in previous studies showing that TSP-1 can induce apoptosis of cells and that TSP-1 is hypoxia-inducible under some culture conditions $[28,29]$. Furthermore, when we directly treated proliferating endothelial cells with recombinant TSP-1, there was suppression of proliferation and induction of apoptosis.

We also have shown that there is more TSP-1 expressed in the dermis and epidermis of patients with SSc than in healthy controls, with staining in keeping with the presence of TSP-1 in keratinocytes and dermal connective tissue. These results are consistent with published data showing that TSP-1 is elevated in SSc [15]. Interestingly, the plasma levels of TSP-1 seen in SSc (mean \pm SEM TSP-1 $27.2 \pm 8.5 \mathrm{ng} / \mathrm{mL}$ ) are close to the levels that we found blocked endothelial cell proliferation and induced apoptosis in cultured endothelial cells.

One interesting result is that despite the induction of VEGF in hypoxia-conditioned media, which would be expected to support cell survival and proliferation, the increased levels of TSP-1 were able to override these protective effects. In support of this idea, TSP-1 has recently been shown to modulate the responses of endothelial cells to VEGF via interaction with the VEGF type 2 receptor [30].

TSP-1 has been studied previously in SSc and TSP-1 gene expression in skin correlates with severity of skin involvement in SSc and has been used in combination with other factors as a biomarker for the disease process [31]. In SSc and control fibroblasts, TSP-1 is induced by culture under hypoxic conditions [32]. In addition, TSP1 activates the latent complex of transforming growth factor $\beta$ (TGF $\beta$ ) and maintains an autocrine loop of stimulation in SSc fibroblast by TGF $\beta$ [33]. It seems likely that TSP-1-dependent effects occur in the hypoxic microenvironment of SSc and that TSP-1 contributes to the microvascular injury and failure of repair and/or angiogenesis, despite the elevation of VEGF in the disease.

\section{Conclusions}

Taken together, our data are consistent with a model wherein injured microvascular cells in SSc fail to repair because of dysregulated induction of TSP-1 in the hypoxic tissues. Antiangiogenic factors can be targeted in future therapeutic approaches, both in SSc and in 
peripheral vascular disease, where TSP-1 is also induced and blocks microvascular repair [34].

\section{Abbreviations}

ABC: avidin-biotin complex; BSA: bovine serum albumin; DMEM: Dulbecco's modified Eagle's medium; ELISA: enzyme-linked immunosorbent assay; FCS: foetal calf serum; HMEC-1: human microvascular endothelial cell 1; PBS: phosphate-buffered saline; qRT-PCR: quantitative real-time polymerase chain reaction; SSC: systemic sclerosis; SV40: simian virus 40; TSP-1: thrombospondin 1; VEGF: vascular endothelial growth factor.

\section{Authors' contributions}

LMR collected patient specimens and wrote the body of the article. JN performed the immunohistochemistry and GPCR analysis. XS performed cell culture and Western blot analysis. AL provided advice regarding matricellular protein biology and oversaw the cell biology experiments. JT provided specialist vascular biology advice and assisted in HMEC-1 culture. DA provided the laboratory facilities and an overview of the experimental protocols and results. RS conceived the study, performed tissue culture experiments and contributed to the writing of the article. All authors read and approved the final manuscript.

\section{Competing interests}

The authors declare that they have no competing interests.

Received: 11 October 2010 Accepted: 2 June 2011

Published: 2 June 2011

\section{References}

1. Varga J, Abraham D: Systemic sclerosis: a prototypic multisystem fibrotic disorder. J Clin Invest 2007, 117:557-567.

2. Kahaleh MB, Sherer GK, LeRoy EC: Endothelial injury in scleroderma. J Exp Med 1979, 149:1326-1335.

3. Carvalho D, Savage CO, Black CM, Pearson JD: IgG antiendothelial cell autoantibodies from scleroderma patients induce leukocyte adhesion to human vascular endothelial cells in vitro: induction of adhesion molecule expression and involvement of endothelium-derived cytokines. J Clin Invest 1996, 97:111-119.

4. Sgonc R, Gruschwitz MS, Boeck G, Sepp N, Gruber J, Wick G: Endothelial cell apoptosis in systemic sclerosis is induced by antibody-dependent cell-mediated cytotoxicity via CD95. Arthritis Rheum 2000, 43:2550-2562.

5. Worda M, Sgonc R, Dietrich $H$, Niederegger $H$, Sundick RS, Gershwin ME, Wick G: In vivo analysis of the apoptosis-inducing effect of antiendothelial cell antibodies in systemic sclerosis by the chorioallantoic membrane assay. Arthritis Rheum 2003, 48:2605-2614.

6. Ahmed SS, Tan FK, Arnett FC, Jin L, Geng YJ: Induction of apoptosis and fibrillin 1 expression in human dermal endothelial cells by scleroderma sera containing anti-endothelial cell antibodies. Arthritis Rheum 2006, 54:2250-2262.

7. Stein CM, Tanner SB, Awad JA, Roberts LJ, Morrow JD: Evidence of free radical-mediated injury (isoprostane overproduction) in scleroderma. Arthritis Rheum 1996, 39:1146-1150.

8. Ogawa F, Shimizu K, Muroi E, Hara T, Hasegawa M, Takehara K, Sato S: Serum levels of 8-isoprostane, a marker of oxidative stress, are elevated in patients with systemic sclerosis. Rheumatology (Oxford) 2006, 45:815-818.

9. Dooley A, Gao B, Bradley N, Abraham DJ, Black CM, Jacobs M, Bruckdorfer KR: Abnormal nitric oxide metabolism in systemic sclerosis: increased levels of nitrated proteins and asymmetric dimethylarginine. Rheumatology (Oxford) 2006, 45:676-684.

10. Nuttall A, Derrett-Smith E, Stratton R: Vascular disease in scleroderma. In Advances in Vascular Medicine. Edited by: Abraham A, Handler C, Dashwood M, Coghlan JG. Berlin: Springer; 2010:315-334.

11. Distler $\mathrm{O}$, Distler JH, Scheid A, Acker T, Hirth A, Rethage J, Michel BA, Gay RE, Müller-Ladner U, Matucci-Cerinic M, Plate KH, Gassmann M, Gay S: Uncontrolled expression of vascular endothelial growth factor and its receptors leads to insufficient skin angiogenesis in patients with systemic sclerosis. Circ Res 2004, 95:109-116.
12. Davies CA, Jeziorska M, Freemont AJ, Herrick AL: The differential expression of VEGF, VEGFR-2 and GLUT-1 proteins in disease subtypes of systemic sclerosis. Hum Pathol 2006, 37:190-197.

13. Hummers LK, Hall A, Wigley FM, Simons M: Abnormalities in the regulators of angiogenesis in patients with scleroderma. J Rheumatol 2009, 36:576-582.

14. Hebbar M, Peyrat JP, Hornez L, Hatron PY, Hachulla E, Devulder B: Increased concentrations of the circulating angiogenesis inhibitor endostatin in patients with systemic sclerosis. Arthritis Rheum 2000, 43:889-893.

15. Macko RF, Gelber AC, Young BA, Lowitt MH, White B, Wigley FM, Goldblum SE: Increased circulating concentrations of the counteradhesive proteins SPARC and thrombospondin-1 in systemic sclerosis (scleroderma): relationship to platelet and endothelial cell activation. J Rheumatol 2002, 29:2565-2570.

16. Mulligan-Kehoe MJ, Drinane MC, Mollmark J, Casciola-Rosen L, Hummers LK Hall A, Rosen A, Wigley FM, Simons M: Antiangiogenic plasma activity in patients with systemic sclerosis. Arthritis Rheum 2007, 56:3448-3458.

17. Ades EW, Candal FJ, Swerlick RA, George VG, Summers S, Bosse DC, Lawley TJ: THMEC-1: establishment of an immortalized human microvascular endothelial cell line. J Invest Dermatol 1992, 99:683-690.

18. Lawler JW, Slayter HS, Coligan JE: Isolation and characterization of a high molecular weight glycoprotein from human blood platelets. J Biol Chem 1978, 253:8609-8616.

19. Bornstein $P$ : Thrombospondins: structure and regulation of expression. FASEB J 1992, 6:3290-3299.

20. Bentley AA, Adams JC: The evolution of thrombospondins and their ligand-binding activities. Mol Biol Evol 2010, 27:2187-2197.

21. Mumby SM, Raugi GJ, Bornstein P: Interactions of thrombospondin with extracellular matrix proteins: selective binding to type $\mathrm{V}$ collagen. $J$ Cell Biol 1984, 98:646-652.

22. Lahav J, Schwartz MA, Hynes RO: Analysis of platelet adhesion with a radioactive chemical crosslinking reagent: interaction of thrombospondin with fibronectin and collagen. Cell 1982, 31:253-262.

23. Mosher DF, Doyle MJ, Jaffe EA: Synthesis and secretion of thrombospondin by cultured human endothelial cells. J Cell Biol 1982 93:343-348.

24. Wikner NE, Dixit VM, Frazier WA, Clark RA: Human keratinocytes synthesize and secrete the extracellular matrix protein, thrombospondin. J Invest Dermatol 1987, 88:207-211.

25. Savill J, Hogg N, Ren Y, Haslett C: Thrombospondin cooperates with CD36 and the vitronectin receptor in macrophage recognition of neutrophils undergoing apoptosis. J Clin Invest 1992, 90:1513-1522.

26. Agah A, Kyriakides TR, Lawler J, Bornstein P: The lack of thrombospondin-1 (TSP1) dictates the course of wound healing in double-TSP1/TSP2-null mice. Am J Pathol 2002, 161:831-839.

27. Kopp HG, Hooper AT, Broekman MJ, Avecilla ST, Petit I, Luo M, Milde T, Ramos CA, Zhang F, Kopp T, Bornstein P, Jin DK, Marcus AJ, Rafii S: Thrombospondins deployed by thrombopoietic cells determine angiogenic switch and extent of revascularization. J Clin Invest 2006, 116:3277-3291.

28. Nör JE, Mitra RS, Sutorik MM, Mooney DJ, Castle VP, Polverini PJ: Thrombospondin-1 induces endothelial cell apoptosis and inhibits angiogenesis by activating the caspase death pathway. J Vasc Res 2000, 37:209-218.

29. Phelan MW, Forman LW, Perrine SP, Faller DV: Hypoxia increases thrombospondin-1 transcript and protein in cultured endothelial cells. J Lab Clin Med 1998, 132:519-529.

30. Zhang X, Kazerounian S, Duquette M, Perruzzi C, Nagy JA, Dvorak HF, Parangi S, Lawler J: Thrombospondin-1 modulates vascular endothelial growth factor activity at the receptor level. FASEB J 2009, 23:3368-3376.

31. Farina $G$, Lafyatis $D$, Lemaire $R$, Lafyatis $R$ : A four-gene biomarker predicts skin disease in patients with diffuse cutaneous systemic sclerosis. Arthritis Rheum 2010, 62:580-588.

32. Distler JH, Jüngel A, Pileckyte M, Zwerina J, Michel BA, Gay RE, KowalBielecka O, Matucci-Cerinic M, Schett G, Marti HH, Gay S, Distler O: Hypoxiainduced increase in the production of extracellular matrix proteins in systemic sclerosis. Arthritis Rheum 2007, 56:4203-4215.

33. Mimura $Y$, Ihn H, Jinnin $M$, Asano $Y$, Yamane $K$, Tamaki K: Constitutive thrombospondin-1 overexpression contributes to autocrine transforming 
growth factor- $\beta$ signaling in cultured scleroderma fibroblasts. Am $J$ Pathol 2005, 166:1451-1463.

34. Favier J, Germain S, Emmerich J, Corvol P, Gasc JM: Critical overexpression of thrombospondin 1 in chronic leg ischaemia. J Pathol 2005, 207:358-366

doi:10.1186/1755-1536-4-13

Cite this article as: Morgan-Rowe et al:: Thrombospondin 1 in hypoxiaconditioned media blocks the growth of human microvascular endothelial cells and is increased in systemic sclerosis tissues.

Fibrogenesis \& Tissue Repair 2011 4:13.

Submit your next manuscript to BioMed Central and take full advantage of:

- Convenient online submission

- Thorough peer review

- No space constraints or color figure charges

- Immediate publication on acceptance

- Inclusion in PubMed, CAS, Scopus and Google Scholar

- Research which is freely available for redistribution

Submit your manuscript at www.biomedcentral.com/submit 